\title{
An equation to estimate 24 -hour total urine protein excretion rate in patients who underwent urine protein testing
}

Fan Yang ${ }^{1 \dagger}$, Jing-Song Shi ${ }^{1 \dagger}$, Si-Wen Gong ${ }^{2}$, Xiao-Dong Xu' ${ }^{1}$ and Wei-Bo Le 1* $^{*}$

\begin{abstract}
Background: The urine protein-creatinine ratio (UPCR) in a spot first-morning urine sample is used to estimate 24-h urine proteinuria (24hUP) in patients who underwent urine protein testing. UPCR cannot be directly compared with 24-h proteinuria. Thus, an equation to estimate 24 -h total protein excretion rate, using age, gender, and the UPCR may improve its bias and accuracy in patients who underwent urine protein testing.

Methods: We simultaneously measured 24-h urine protein and the same day's first-morning spot urine from patients with kidney disease. Generalized linear and no-linear models, using age, gender, and UPCR, were constructed to estimate for 24-h urine protein and the best model (NJ equation) was selected to estimated $24 \mathrm{hUP}$ (e24hUP).

Results: A total of 5435 paired samples (including a training cohort of 3803 patients and a validation cohort of 1632 patients) were simultaneously measured for UPCR and 24-h urine protein. In the training cohort, the unadjusted UPCR obviously underestimated 24-h urine protein when UPCR $\leq 1.2 \mathrm{~g} / \mathrm{g}$ (median bias $-0.17 \mathrm{~g} / 24 \mathrm{~h}$ ) and overestimated 24-h urine protein when UPCR $>1.2 \mathrm{~g} / \mathrm{g}$ (median bias $0.53 \mathrm{~g} / 24 \mathrm{~h}$ ). In the validation cohort, the NJ equation performed better than the unadjusted UPCR, with lower root mean square error ( 0.81 vs. 1.02, $P<0.001$ ), less bias (median difference between measured and estimated urine protein, -0.008 vs. 0.12), improved precision (interquartile range of the differences, 0.34 vs. 0.50 ), and greater accuracy (percentage of estimated urine protein within $30 \%$ of measured urine protein, $53.4 \%$ vs. 32.2\%). Bland-Altman plot indicated that the agreement of spot and daily estimates was less pronounced with $24 \mathrm{hUP}>2 \mathrm{~g}$ than lower values.
\end{abstract}

Conclusions: The NJ e24hUP equation is more accurate than unadjusted UPCR to estimate $24 \mathrm{hUP}$ in patients with kidney disease and could be used for laboratory application.

Keywords: Urine protein-creatinine ratio, Proteinuria, Prediction model

\section{Background}

Proteinuria is a common feature of chronic nephropathies, and those with greater levels of proteinuria are at greater risk of declining in glomerular filtration rate, as

\footnotetext{
*Correspondence: leweibo@gmail.com

${ }^{\dagger}$ Fan Yang and Jing-Song Shi contributed equally to this work.

${ }^{1}$ National Clinical Research Center of Kidney Diseases, Jinling Hospital,

Nanjing University School of Medicine, Zhongshan East Street 305,

Nanjing, China

Full list of author information is available at the end of the article
}

well as progression to end-stage renal disease (ESRD) [1]. Quantitative assessment of urinary protein excretion is critical in patients with proteinuric kidney disease. Urinary protein excretion rate has been traditionally measured using 24-h urine collections. The 24-h urine protein (24hUP) is considered as the gold standard for measurement of protein excretion in patients with proteinuric kidney disease. However, a 24-h urine collection is cumbersome for patients and frequently collected incorrectly. Such collection errors are problematic because the error 
in estimating 24-h proteinuria from the protein content of intended 24-h collections is directly proportional to the extent of over collection or under collection [2, 3]. Moreover, collection of 24-h urine in the hospital can cause spread of some species of bacteria, such as multidrug-resistant Pseudomonas aeruginosa, which causes urinary tract infection $[4,5]$. As previous studies indicated, the urine protein-creatinine ratio (UPCR) in a single spot first-morning urine sample, could serve as a convenient and satisfactory substitute for the determination of protein excretion in 24-h urine collection [6, 7].

Although UPCR is recognized as a screening tool for patients with proteinuric kidney diseases, the raw unadjusted UPCR cannot be directly compared with 24-h proteinuria in patients with proteinuric kidney diseases. The urine protein and creatinine excretion can vary throughout the day and UPCR is remarkably influenced by the urine creatinine excretion [8-11]. Several equations which adjust gender, age and/or other variables to estimate 24hUP may improve its bias and accuracy in patients with proteinuric kidney disease [12-14]. However, the relationship between UPCR and 24hUP may differ across races and clinical centers. In this study, we assessed the correlation between first-morning spot UPCR and 24 hUP from 5435 paired urine samples with diverse degrees of proteinuria. We developed an equation (Named NJ equation) to estimate $24 \mathrm{hUP}$ based on UPCR, age, and gender in our renal center.

\section{Methods}

\section{Study subjects and laboratory measurements}

Patients who had visited National Clinical Research Center of Kidney Diseases, Jinling Hospital between May of 2019 and December of 2020, were screened in this study. A total of 5526 patients with both intact UPCR and $24 \mathrm{hUP}$ test results were referred. Exclusion criteria included the following: (1) being aged < 18 years; (2) $24 \mathrm{~h}$ urine amount $<400 \mathrm{~mL}$; (3) having UPCR $>15 \mathrm{~g} / \mathrm{g}$ or $24 \mathrm{hUP}>15 \mathrm{~g}$. Finally, 5435 patients were enrolled for data analysis. The whole cohort was randomly divided into two cohorts with a ratio of 7:3, namely the training cohort (3803 patients) and the validation cohort (1632 patients).

All patients were instructed to begin collecting urine in the container and to collect all urine continuously for $24 \mathrm{~h}$. All examination experiments were conducted in the central laboratory at our hospital. The first-morning midstream urine sample was collected to test UPCR. The volume of collected 24-h urine was measured by the laboratory staff, and protein level in samples taken from 24-h urine collections was determined using standard laboratory methods in the central laboratory at our hospital (Cobas Integra analyzers, Roche). The spot urine specimen was assayed for urine protein concentration and urine creatinine concentration. The UPCR was calculated by dividing the urine protein concentration by the creatinine concentration.

\section{Equation derivation and equation performance}

UPCR was log transformed or square-root transformed. The form with better correlation coefficient with 24hUP was chosen in the candidate $24 \mathrm{hUP}$ estimation equations. Several candidate equations were derived using least squares regression. Age and gender could be included in the candidate equations, while body surface area indexing (BSA) was not included in the equations for BSA is often unavailable in laboratory application. Generalized linear smooths (glm) or local smooths (loess) were used to observe the relationship between $24 \mathrm{hUP}$ and predictive variables. In general, the model with the smallest RMSE (root mean square error) was preferred and was carried forward in the validation cohort. Interactions for square-root transforming UPCR and gender, as well as for square-root transforming UPCR and age, were also included in the regression model if they were significant $(P<0.001)$ and improved model performance (with lower RMSE).

Bias (Median difference), precision, and accuracy were calculated to determine equation performance, as proposed in other similar studies $[15,16]$. Bias was defined as the median difference between the measured $24 \mathrm{hUP}$ (m24hUP) and the e24hUP, while precision, reflected by an IQR (interquartile range) of this difference. A positive value of bias indicates that the equation overestimates $24 \mathrm{hUP}$, and a negative value indicates underestimation. Accuracy was assessed as the RMSE relative to m24hUP. P30 is defined as the percentages of individuals that are within $30 \%$ difference from the m24hUP. Bootstrap methods (2000 bootstraps) were used to compute $95 \%$ CIs for these four equation performances. The degree of agreement was validated by Bland-Altman analysis. We used the area under receiver-operating characteristic curve (AUROC) at different specified thresholds $(>0.15,>0.5$, $>3.5 \mathrm{~g} / 24 \mathrm{~h}$ ) according to the thresholds recommended by KDIGO to measure the diagnostic value of $\mathrm{NJ}$ equation [1]. After the best Youden's index was calculated, the according sensitivity, specificity, positive likelihood ratio, and negative likelihood ratio were identified. Accuracy was defined as the proportion of patients correctly classified according to unadjusted UPCR and e24hUP calculated by NJ equation above specific m24hUP thresholds in the entire ROC analysis.

Kolmogorov-Smirnov test was conducted to determine whether variables involved in our study were normally distributed. Normally distributed variables are expressed as mean \pm sd. and were compared using Student's t-test 
or one-way analysis of variance. Skewedly distributed variables are expressed as median and range and compared using either Mann-Whitney U test or KruskalWallis $\mathrm{H}$ test. Categorical variables are expressed in percentages and compared using the Pearson $\chi^{2}$ test or Fisher's exact test. Correlation between two variables were determined by Pearson correlation test. Two-tailed $P<0.01$ findings were considered statistically significant. There were no missing data in this study. All analyses were carried out using $R$ version 4.0.2 (Free Software Foundation, Boston, Massachusetts).

\section{Results}

\section{Clinical and demographic characteristics of the study} population

From May 2019 to December 2020, 5435 patients who visited National Clinical Research Center of Kidney Diseases, Jinling Hospital between were enrolled in this study. The whole cohort was randomly divided into the training cohort and the validation cohort with a ratio of $7: 3$. Table 1 shows the demographic and clinical characteristics of these two cohorts. The median age of patients in the training and validation cohort were 48 (lower quartile - upper quartile: $36-56)$ vs 48 years (lower quartile - upper quartile: $36-56)(P=0.676)$. In the training cohort, median $24 \mathrm{hUP}$ was $0.63 \mathrm{~g} / 24 \mathrm{~h}$ (lower quartile upper quartile: $0.34-1.32$ ), with no significant difference from the validation cohort $(0.62 \mathrm{~g} / 24 \mathrm{~h}$, lower quartile upper quartile:0.34-1.37, $P=0.701)$. Similarly, there is no significant difference between these two cohorts in gender ratio, urine protein, urine creatinine, UPCR, and 24 h urine amount $(P=0.947,0.856,0.707,0.854$, and 0.926 , respectively).

\section{Correlations between UPCR and 24-h urine protein (24hUP)} in the training cohort

There was a strong correlation between UPCR and 24hUP in the training cohort (Pearson correlation coefficient $=0.85)($ Fig. 1a). Overall, the UPCR underestimated the $24 \mathrm{hUP}$ (bias $=-0.12 \mathrm{~g} / 24 \mathrm{~h}$ ). More precisely, the UPCR underestimated $24 \mathrm{hUP}$ when UPCR $\leq 1.2 \mathrm{~g} / \mathrm{g}$ (bias $=-0.17 \mathrm{~g} / 24 \mathrm{~h}$ ), but obviously overestimated $24 \mathrm{hUP}$ when UPCR $>1.2 \mathrm{~g} / \mathrm{g}$ (bias $=0.53 \mathrm{~g} / 24 \mathrm{~h}$ ) (Fig. $1 \mathrm{~b}$ ). In the training cohort, UPCR and $24 \mathrm{hUP}$ were strongly correlated when patients were stratified by age (Pearson correlation coefficient $=0.85$ for patients $<48$ years old and 0.86 for patients $\geq 48$ years old, respectively)and gender (Pearson correlation coefficient $=0.87$ for male and 0.84 for female, respectively) (Supplementary Table 1).

\section{Construction of the equations to estimate $24 \mathrm{hUP}$}

Square-root transformed UPCR and 24hUP strengthened the Pearson correlation coefficient to 0.88 , better than the log-transformed ones (Pearson correlation coefficient $=0.86$ ). Thus, UPCR and $24 \mathrm{hUP}$ were both transformed into square-root scale in the following analysis. Several candidate equations were developed to estimate 24hUP (Table 2). We focused on RMSE to select the best model. Among the models, the model 4, named as NJ equation, showed the best performance, with the lowest RMSE in the training cohort. Although both the interaction between square-root transformed UPCR and age $(P<0.001)$ and interaction between square-root transformed UPCR and gender $(P<0.001)$ were significant in the model 4, involvement of either or both of them in the model 4 failed to decrease RMSE. Thus, the model without interactions was carried forward for further analysis. The exact model 4 (the NJ equation) for estimating 24hUP in a Chinese population as follows:

For Female:

$$
(0.623 \times \sqrt{U P C R}+0.0323 \times U P C R-0.0024 \times a g e+0.381)^{2}
$$

For Male:

$$
(0.623 \times \sqrt{U P C R}+0.0323 \times U P C R-0.0024 \times \text { age }+0.522)^{2}
$$

\begin{tabular}{|c|c|c|c|c|}
\hline Variables & Total $(n=5435)$ & Training cohort $(n=3803)$ & Validation cohort $(n=1632)$ & $P$ \\
\hline Age, Median (IQR), y & $48(36,56)$ & $48(36,56)$ & $48(36,56)$ & 0.676 \\
\hline Gender, n(\%) & & & & 0.947 \\
\hline Female & $2593(47.7)$ & $1816(47.8)$ & $777(47.6)$ & \\
\hline Male & $2842(52.3)$ & $1987(52.2)$ & $855(52.4)$ & \\
\hline UP, Median (IQR), g/L & $0.57(0.16,1.66)$ & $0.56(0.16,1.67)$ & $0.58(0.15,1.65)$ & 0.856 \\
\hline UCRE, Median (IQR), g/L & $1.18(0.77,1.77)$ & $1.17(0.77,1.79)$ & $1.19(0.76,1.74)$ & 0.707 \\
\hline UPCR, Median (IQR), g/g & $0.49(0.14,1.49)$ & $0.49(0.14,1.49)$ & $0.49(0.14,1.49)$ & 0.854 \\
\hline 24hUA, Median (IQR), mL & $1800(1400,2300)$ & $1800(1400,2300)$ & $1800(1400,2300)$ & 0.926 \\
\hline 24hUP, Median (IQR), g/24h & $0.62(0.34,1.33)$ & $0.63(0.34,1.32)$ & $0.62(0.34,1.37)$ & 0.701 \\
\hline
\end{tabular}

Table 1 Demographic and clinical characteristics of patients in the training and validation cohort

$I Q R$ interquartile range, UP urine protein, UCRE urine creatinine, UPCR urine protein-creatinine ratio, 24hUA 24-h urine amount, 24hUP 24-h urine protein 

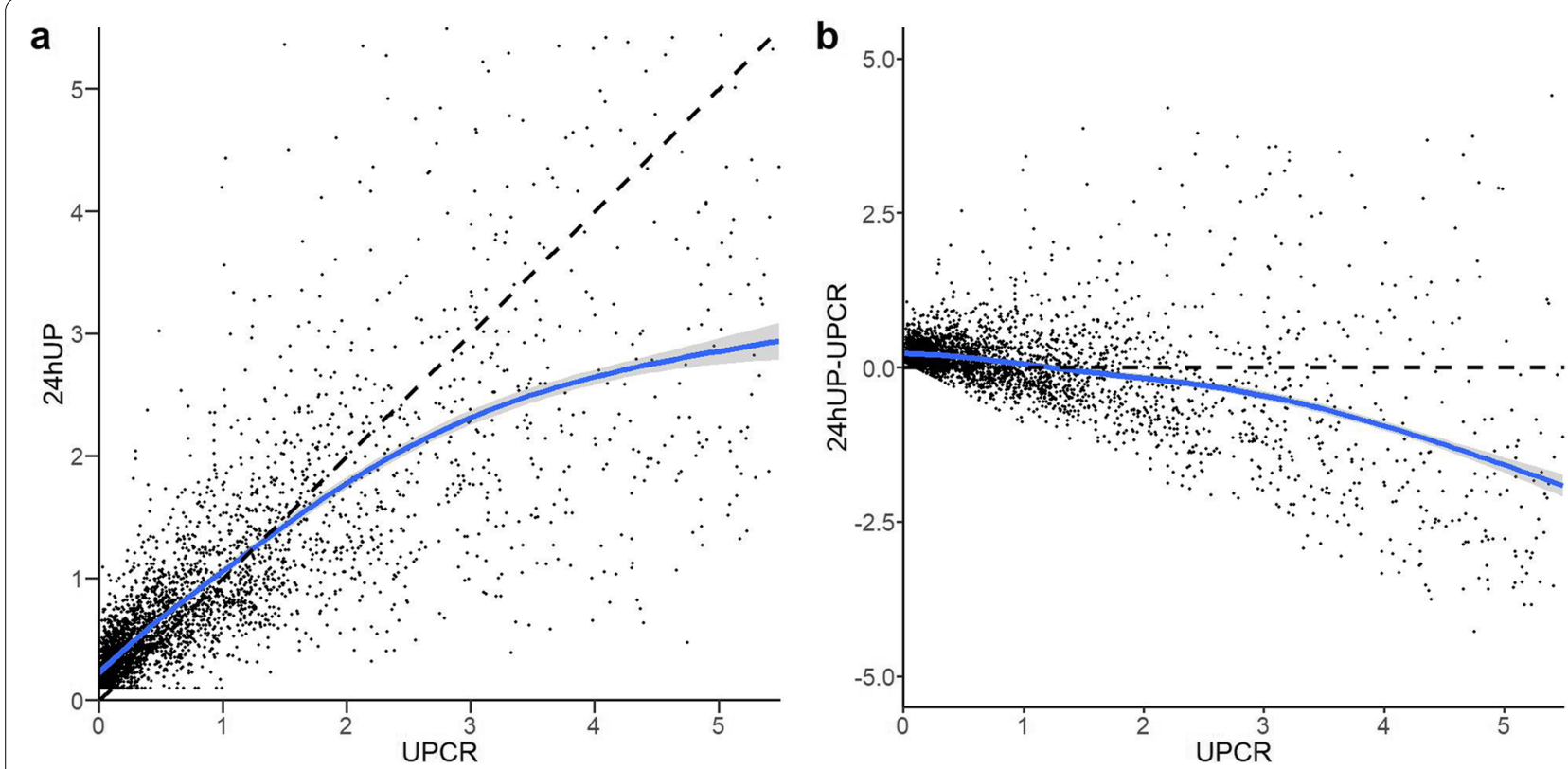

Fig. 1 Scatter plot of $24 \mathrm{hUP}$ and UPCR (a) /24hUP-UPCR (b). 24hUP, 24-h urine protein; UPCR, urine protein-creatinine ratio

\section{Performance of the $\mathrm{NJ}$ equation}

As shown in Table 3, the NJ equation in the training cohort improved median bias compared with unadjusted UPCR $(-0.010 \mathrm{~g} / 24 \mathrm{~h}$ vs. $0.12 \mathrm{~g} / 24 \mathrm{~h}, P<0.001)$, as well as IQR $(0.36 \mathrm{~g} / 24 \mathrm{~h}$ vs. $0.35 \mathrm{~g} / 24 \mathrm{~h}, P<0.001)$, P30 (52.5\% vs. $31.0 \%, P<0.001)$, and RMSE (0.88 vs. $1.10, P<0.001)$.

RMSE, Bias, IQR and P30 were all presented as values (95\% confidence intervals).

In the validation cohort, the $\mathrm{NJ}$ equation also had significantly lower RMSE ( 0.81 vs. $1.02, P<0.001)$, lower median bias $(-0.008 \mathrm{~g} / 24 \mathrm{~h}$ vs. $0.12 \mathrm{~g} / 24 \mathrm{~h}, P<0.001)$, lower IQR $(0.34 \mathrm{~g} / 24 \mathrm{~h}$ vs. $0.47 \mathrm{~g} / 24 \mathrm{~h}, P<0.001)$, and higher P30 (53.4\% vs. 32.2\%, $P<0.001)$ than unadjusted UPCR. As shown by the Bland-Altman plot, the 95\% CI limit of agreement between spot estimated 24hUP (by $\mathrm{NJ}$ equation) and measured 24hUP were narrower than that between unadjusted UPCR and measured 24hUP,

Table 2 Candidate Regression Models for 24 hUP and RMSE value in the training cohort

\begin{tabular}{lll}
\hline ID & Models & RMSE \\
\hline 0 & UPCR & 1.10 \\
1 & $\beta_{0}+\beta_{1} \times$ UPCR & 0.91 \\
2 & $\left(\beta_{0}+\beta_{1} \times \sqrt{U P C R} \text { square root of UPCR }\right)^{2}$ & 0.93 \\
3 & $\left(\beta_{0}+\beta_{1} \times \sqrt{U P C R}\right.$ square root of UPCR $+\beta_{2} \times$ gender + & 0.89 \\
& $\beta_{3} \times$ age $)^{2}$ & \\
4 & $\left(\beta_{0}+\beta_{1} \times \sqrt{U P C R}\right.$ square root of UPCR $+\beta_{2} \times$ gender + & 0.88 \\
& $\beta_{3} \times$ age $+\beta_{4} \times$ UPCR $)^{2}$ & \\
5 & $\left(\beta_{0}+\left(\beta_{1}+\beta_{2} \times\right.\right.$ gender $+\beta_{3} \times$ age $) \times \sqrt{U P C R}$ square root & 0.88 \\
& of UPCR $)^{2}$ & \\
\hline
\end{tabular}

UPCR urine protein-creatinine ratio both in the training and validation cohort (Fig. 2). Bland-Altman plot also indicated that the agreement of spot and daily estimates was less pronounced with 24 hUP $>2$ g than lower values, both in the training and validation cohort (Fig. 2). Stratified analysis of the validation cohort indicated that the NJ equation also performed better than the unadjusted UPCR in subgroups defined by age and gender (all $P$ values $<0.001$ ) (shown in Supplementary Table 2).

Table 3 Comparison of the UPCR and NJ Equations in estimating measured 24-h urine protein

\begin{tabular}{lll}
\hline $\begin{array}{l}\text { Variable and } \\
\text { Equation }\end{array}$ & Training cohort & Validation cohort \\
\hline $\begin{array}{l}\text { RMSE }(95 \% \mathrm{Cl}) \\
\text { UPCR }\end{array}$ & $1.10(1.03,1.17)$ & $1.02(0.91,1.12)$ \\
$\quad$ NJ Equation & $0.88(0.82,0.94)$ & $0.81(0.73,0.89)$ \\
Bias (95\% Cl) & & \\
UPCR & $0.12(0.11,0.13)$ & $0.12(0.10,0.13)$ \\
NJ Equation & $-0.010(-0.020$, & $-0.008(-0.022,0.004)$ \\
IQR (95\% Cl) & $-0.001)$ & \\
UPCR & $0.46(0.43,0.49)$ & $0.47(0.41,0.53)$ \\
NJ Equation & $0.35(0.33,0.36)$ & $0.34(0.30,0.36)$ \\
P30(\%) (95\% Cl) & & \\
UPCR & $31.0(29.4,32.6)$ & $32.2(29.9,34.5)$ \\
NJ Equation & $52.5(50.8,54.0)$ & $53.4(50.7,56.1)$ \\
\hline
\end{tabular}

RMSE root mean square error, $\mathrm{Cl}$ confidence interval, UPCR urine proteincreatinine ratio, $I Q R$ interquartile range, $P 30$ percentages of individuals that are within $30 \%$ difference 


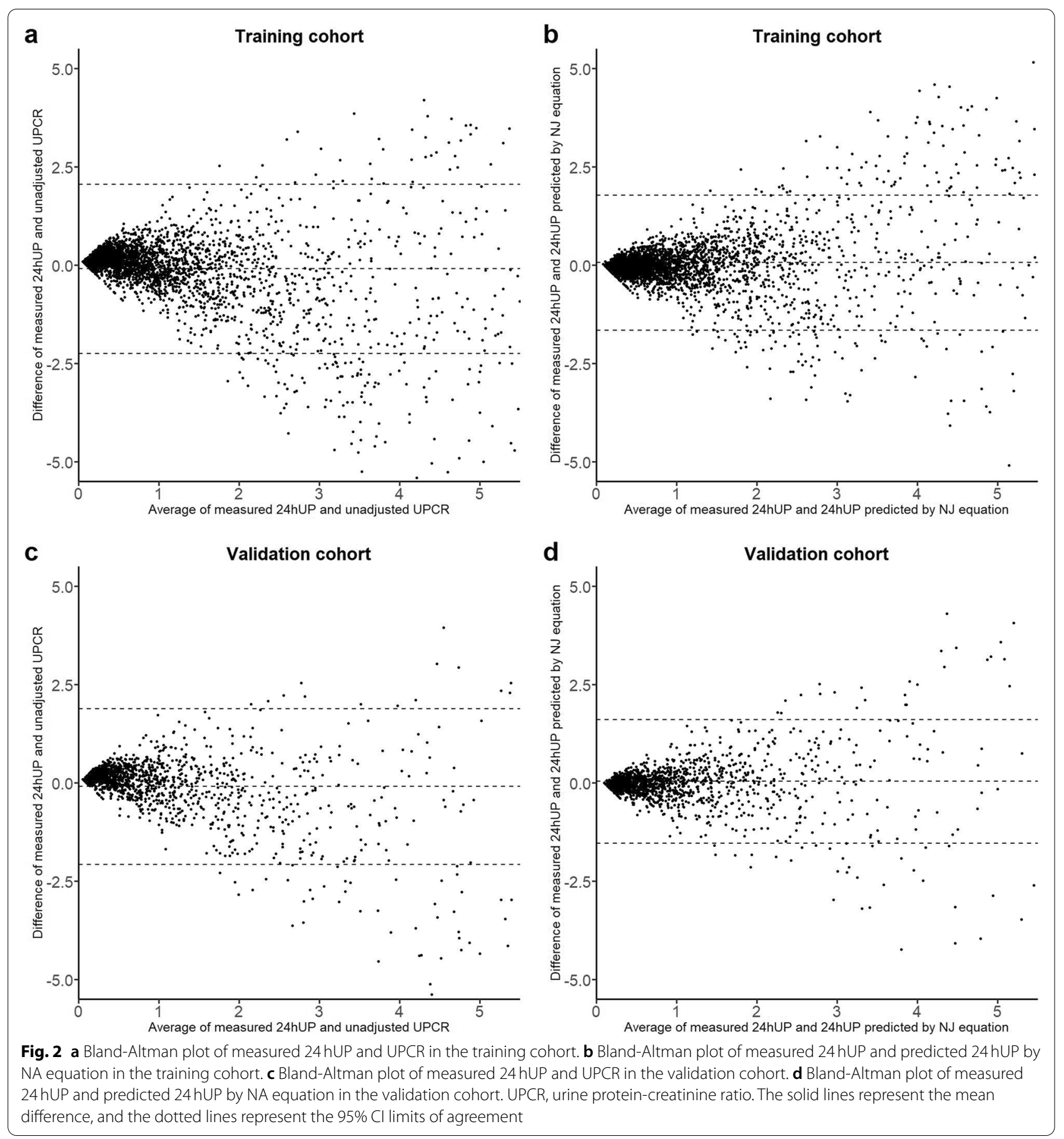

To further clarify the diagnostic value of $\mathrm{NJ}$ equation among situations of different degrees of proteinuria, we stratified the validation cohort by $24 \mathrm{hUP}$, with thresholds of $0.15 \mathrm{~g}, 0.5 \mathrm{~g}$, and $3.5 \mathrm{~g}$, respectively. A spot UPCR $>2.21 \mathrm{~g} / \mathrm{g}$ represents threshold to correlate with a $24 \mathrm{hUP}$ of $>3.5 \mathrm{~g}$ (positive likelihood ratio of 11.64, negative likely ratio of 0.05 , accuracy of 0.91 , and AUC of 0.98 , shown in Supplementary Table 3). The ROC curves to detect $24 \mathrm{hUP}$ values above thresholds of $0.15 \mathrm{~g}, 0.5 \mathrm{~g}$ and $3.5 \mathrm{~g}$ did not differ between unadjusted UPCR and e24hUP by $\mathrm{NJ}$ equation (Fig. 3). The areas under the ROC curves of unadjusted UPCR and $24 \mathrm{hUP}$ by NJ equation were 0.88 
vs $0.86(P=0.021), 0.94$ vs $0.94(P<0.539), 0.98$ vs 0.97 $(P=0.002)$, respectively in the validation cohort. (shown in Supplementary Table 3).

\section{Discussion}

Quantification of urinary protein excretion is the cornerstone for the diagnosis and prediction of the outcome of glomerular diseases. The $24 \mathrm{hUP}$ is the gold standard for measurement of protein excretion and is used in most clinical trials and clinical guidelines of nephrology, but sample collection is associated with several technical problems such as inaccurate collection and the potential spread of drug-resistant pathogens [2-5]. The measurement of UPCR is much easier than 24hUP for patients and has become a popular alternative of the $24 \mathrm{hUP}$. Several previous studies showed a strong correlation between UCR and 24hUP in patients with CKD or normal kidney function [3, 6, 17-19]. However, in our center, medical practitioners tend to refer to $24 \mathrm{hUP}$ rather than UPCR when developing diagnosis and treatment strategies. In this study, we assessed the correlation between first-morning spot UPCR and 24hUP from realworld data and confirmed a good correlation between the UPCR and 24hUP in patients who visited our renal center. However, there was a systemic bias between UPCR and 24hUP: the UPCR underestimated the 24hUP (bias $-0.12 \mathrm{~g} / 24 \mathrm{~h}$ ). Thus, the UPCR cannot be directly compared with 24-h proteinuria in patients who underwent urine protein testing.
To improve the accuracy of $24 \mathrm{hUP}$ prediction from a single spot UPCR, we developed an accurate prediction equation integrating demographic variables including age and gender. Several candidate models were derived and the model with the smallest RMSE (NJ equation) was chosen. The NJ equation also decreased the bias, IQR, and P30 compared with unadjusted UPCR, both in the training and validation cohort. After stratification by age and gender, the $\mathrm{NJ}$ equation still performed better than unadjusted UPCR.

Several previous studies also constructed models to predict 24 hUP based on a single spot UPCR [9, 12-14, $20,21]$. Chen et al. [12] constructed a 24 hUP prediction model with 1243 CKD patients in total based on morning spot UPCR, gender, age, body weight, and CKD stage. Compared with NJ equation, this model was inconvenient to apply, because bodyweight and CKD stage were not readily accessible in laboratory application. They found that spot UPCR can accurately predict $24 \mathrm{hUP}$ in patients with lower $24 \mathrm{hUP}(<3 \mathrm{~g} / 24 \mathrm{~h})$. This was consistent with the results of our Bland-Altman plot, which indicated that $\mathrm{NJ}$ Equation performed better in patients with $24 \mathrm{hUP}<2 \mathrm{~g} / 24 \mathrm{~h}$ than those with higher $24 \mathrm{hUP}$. By comparison, the model constructed by Hogan [9] was simple, with UPCR as the only variable. Hogan enrolled 226 adult CKD patients with biopsy-proven nephrotic diseases, the sample size of which was relatively small, especially when subgroup analyses were conducted. Moreover, the spot urine samples involved in Hogan's
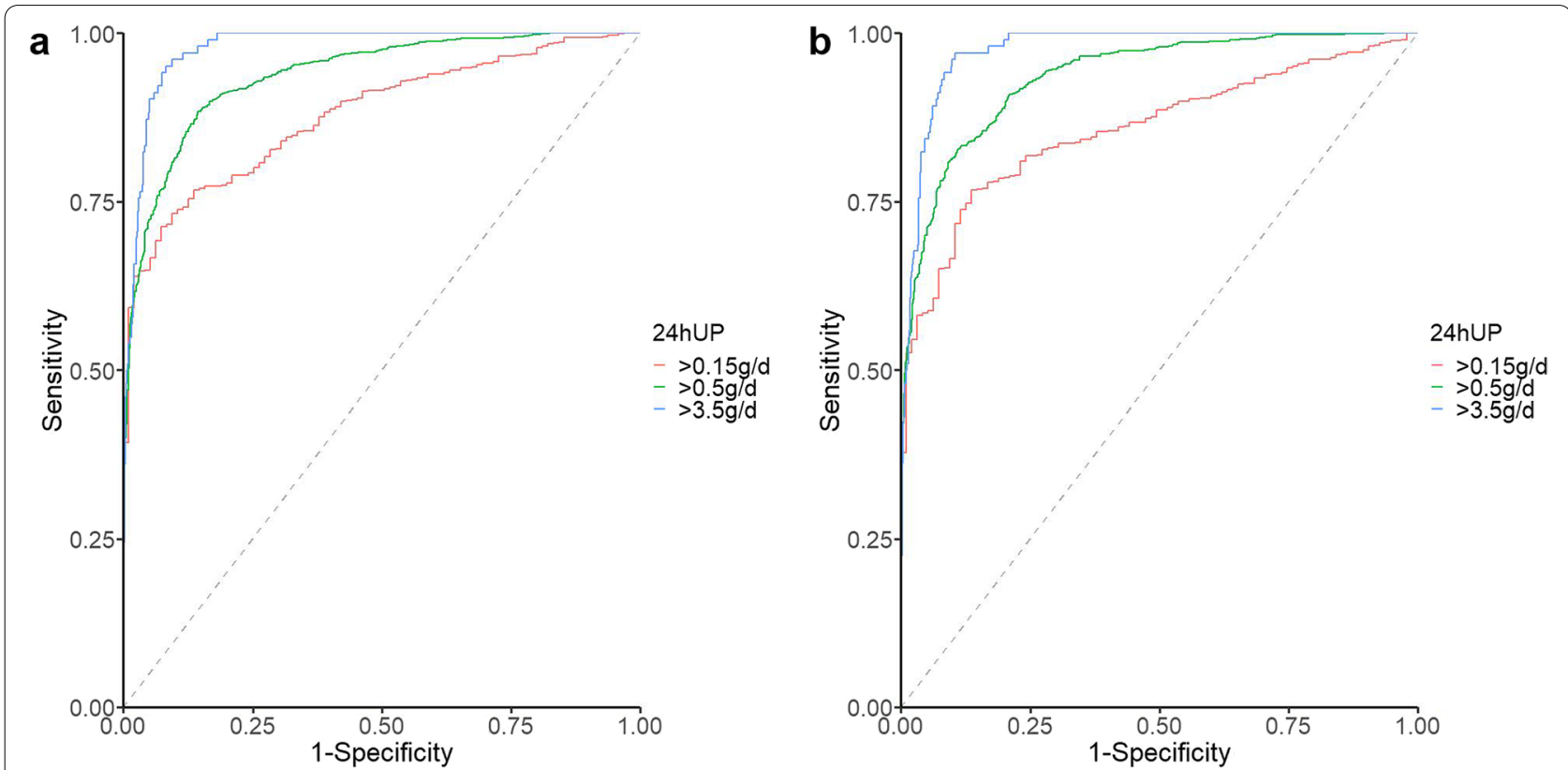

Fig. 3 ROC analysis of the ability of unadjusted UPCR (a) and NJ equation (b) to predict 24 hUP above clinically relevant thresholds in the validation cohort 
study were random, while a prospective study showed that UPCR varies by sampling time during the day for the same patient [8]. In our study, we tried to construct a prediction model for laboratory application, where age and gender were easily accessible. Furthermore, the inclusion of gender and age did decrease the RMSE of the model. Thus, we constructed the prediction model only with UPCR, gender, and age, which could be automatedly applied in the laboratory test reports as a surrogate of UPCR for medical practitioners to refer to.

Here, we reported a $24 \mathrm{hUP}$ prediction model from first-morning UPCR in our renal center, with a relatively large sample size $(n=5435)$. However, several limitations of the study should be addressed. First, due to laboratory application of $\mathrm{NJ}$ equation, confounding factors that have a potential influence on proteinuria were unavailable, nor involved in this study, including fever, diabetes, hypertension, urinary tract infection, indwelling urinary catheter, pregnancy, recipients of dialysis therapy, as well as renal transplant graft. Second, NJ equation was based on creatinine level, which should be used with caution in people with abnormally high or low levels of muscle mass. Third, although some published reports on proteinuric kidney disease were based on albuminuria or albumincreatinine-ratio (ACR) [22, 23], we only report on total protein and not albumin excretion. According to the latest KDIGO guidelines [1], the albumin excretion rate and the ACR are not commonly used in nondiabetic forms of glomerular disease. In addition, the latest KDIGO guidelines further suggested that proteinuria in GN (separate from minimal change disease) is typically heterogeneous and consists of both albumin and other proteins. When a $24 \mathrm{hUP}$ cannot be obtained, alternative method should be used. Furthermore, in clinical practice, albuminuria and 24hUP were both routinely reported by the central laboratory at our hospital for each patient. Medical practitioners in our center prefer to refer to 24hUP instead of albuminuria to determine total protein excretion. Fourth, this study was mainly conducted in the Han population, so the results may not represent what would be seen in a similar study in other ethnic background. Fifth, a previous meta-analysis revealed that spot UPCR has a utility as a screening test for proteinuria in patients with systemic lupus erythematosus, but these two tests showed poor agreement [24]. A spot urine PCR is reliable for $24 \mathrm{hUP}$ prediction in patients with IgA nephropathy, but unreliable in patients with minimal change disease or Membranous glomerulonephritis with nephrotic syndrome [25]. Thus, pathological diagnosis might be a potential confounding factor in the prediction of $24 \mathrm{hUP}$ based on spot UPCR. However, due to lack of diagnostic information by kidney biopsy in some patients, we failed to stratify the patients involved in this study by pathological diagnosis.
Sixth, due to lack of routinely examined creatinine in 24-h urine collections, completement assessment of the collection was not conducted in term of at least $20 \mathrm{mg} / \mathrm{kg}$ creatinine in men $(15 \mathrm{mg} / \mathrm{kg}$ in women).

\section{Conclusions}

In conclusion, the $\mathrm{NJ}$ equation is more accurate for estimating $24 \mathrm{hUP}$ than unadjusted UPCR, as shown in this large Chinese population, could be used for laboratory application in our renal center. This equation performed better in patients with $24 \mathrm{hUP}<2 \mathrm{~g} / 24 \mathrm{~h}$ than those with higher 24hUP. Despite the robustness of our model, further large-scale validation should be needed to establish a universal consensus.

\section{Supplementary Information}

The online version contains supplementary material available at https://doi. org/10.1186/s12882-022-02673-2.

Additional file 1: Supplementary Table 1. Correlation analysis between UPCR and 24 hUP in the training cohort stratified by gender and age. Supplementary Table 2. Comparison of the UPCR and NJ Equations in Estimating Measured 24-h protein in the validation cohort stratified by age and gender. Supplementary Table 3. Threshold of spot UPCR to detect different degrees of 24 hUP in the validation cohort $(n=1624)$.

\section{Acknowledgements}

Not applicable.

\section{Authors' contributions}

FY conducted the statistical analysis and drafted the manuscript. JS, SWG and XDX were responsible for collecting information involved in the study. WBL was responsible for study design and manuscript revision. All authors have read and approved the manuscript.

\section{Funding}

This study was financially supported by the National Natural Science Foundation of China (Grant No. 81970620, 81600560).

\section{Availability of data and materials}

The datasets used and/or analysed during the current study are available from the corresponding author on reasonable request.

\section{Declarations}

Ethics approval and consent to participate

The research protocol was approved by the Institutional Review Board of the Jinling Hospital, Nanjing University, and conducted according to the principles of the Declaration of Helsinki. Due to the retrospective nature of the study, written informed consent for participation was waived by the Institutional Review Board of the Jinling Hospital, Nanjing University.

Consent for publication

Not applicable.

Competing interests

The authors declare that they have no competing interests.

\section{Author details}

${ }^{1}$ National Clinical Research Center of Kidney Diseases, Jinling Hospital, Nanjing University School of Medicine, Zhongshan East Street 305, Nanjing, China. 
${ }^{2}$ National Clinical Research Center of Kidney Diseases, Jinling Hospital, the First School of Clinical Medicine, Southern Medical University, Nanjing, China.

Received: 5 August 2021 Accepted: 12 January 2022

Published online: 29 January 2022

\section{References}

1. Kidney Disease: Improving Global Outcomes Glomerular Diseases Work G. KDIGO 2021 Clinical Practice Guideline for the Management of Glomerular Diseases. Kidney Int. 2021;100(4S):S1-S276.

2. Levey AS, Coresh J, Balk E, Kausz AT, Levin A, Steffes MW, et al. National Kidney Foundation practice guidelines for chronic kidney disease: evaluation, classification, and stratification. Ann Intern Med. 2003;139(2):137-47.

3. Birmingham DJ, Rovin BH, Shidham G, Nagaraja HN, Zou X, Bissell M, et al. Spot urine protein/creatinine ratios are unreliable estimates of $24 \mathrm{~h}$ proteinuria in most systemic lupus erythematosus nephritis flares. Kidney Int. 2007;72(7):865-70.

4. Sekiguchi J, Teruya K, Horii K, Kuroda E, Konosaki H, Mizuguchi Y, et al. Molecular epidemiology of outbreaks and containment of drug-resistant Pseudomonas aeruginosa in a Tokyo hospital. J Infect Chemother. 2007;13(6):418-22.

5. Nagao M, linuma Y, Igawa J, Saito T, Yamashita K, Kondo T, et al. Control of an outbreak of carbapenem-resistant Pseudomonas aeruginosa in a haemato-oncology unit. J Hosp Infect. 2011;79(1):49-53.

6. Ginsberg JM, Chang BS, Matarese RA, Garella S. Use of single voided urine samples to estimate quantitative proteinuria. N Engl J Med. 1983;309(25):1543-6.

7. Bhide A, Rana R, Dhavilkar M, Amodio-Hernandez M, Deshpande D, Caric $V$. The value of the urinary protein:creatinine ratio for the detection of significant proteinuria in women with suspected preeclampsia. Acta Obstet Gynecol Scand. 2015;94(5):542-6.

8. Fine DM, Ziegenbein M, Petri M, Han EC, McKinley AM, Chellini JW, et al. A prospective study of protein excretion using short-interval timed urine collections in patients with lupus nephritis. Kidney Int. 2009;76(12):1284-8.

9. Hogan MC, Reich HN, Nelson PJ, Adler SG, Cattran DC, Appel GB, et al. The relatively poor correlation between random and 24-hour urine protein excretion in patients with biopsy-proven glomerular diseases. Kidney Int. 2016;90(5):1080-9.

10. Mattix HJ, Hsu CY, Shaykevich S, Curhan G. Use of the albumin/creatinine ratio to detect microalbuminuria: implications of sex and race. J Am Soc Nephrol. 2002;13(4):1034-9.

11. Witte EC, Lambers Heerspink HJ, de Zeeuw D, Bakker SJ, de Jong PE, Gansevoort R. First morning voids are more reliable than spot urine samples to assess microalbuminuria. J Am Soc Nephrol. 2009;20(2):436-43.

12. Chen YT, Hsu HJ, Hsu CK, Lee CC, Hsu KH, Sun CY, et al. Correlation between spot and $24 \mathrm{~h}$ proteinuria: derivation and validation of equation to estimate daily proteinuria. PLoS One. 2019;14(4):e0214614.

13. Medina-Rosas J, Gladman DD, Su J, Sabapathy A, Urowitz MB, Touma Z. Utility of untimed single urine protein/creatinine ratio as a substitute for 24-h proteinuria for assessment of proteinuria in systemic lupus erythematosus. Arthritis Res The. 2015;17:296.

14. Talreja H, Akbari A, White CA, Ramsay TO, Hiremath S, Knoll G. Predicting kidney transplantation outcomes using proteinuria ascertained from spot urine samples versus timed urine collections. Am J Kidney Dis. 2014;64(6):962-8.

15. Fotheringham J, Campbell MJ, Fogarty DG, El Nahas M, Ellam T. Estimated albumin excretion rate versus urine albumin-creatinine ratio for the estimation of measured albumin excretion rate: derivation and validation of an estimated albumin excretion rate equation. Am J Kidney Dis. 2014;63(3):405-14.

16. Levey AS, Stevens LA, Schmid CH, Zhang YL, Castro AF 3rd, Feldman HI, et al. A new equation to estimate glomerular filtration rate. Ann Intern Med. 2009;150(9):604-12.

17. Wilmer WA, Rovin BH, Hebert CJ, Rao SV, Kumor K, Hebert LA. Management of glomerular proteinuria: a commentary. J Am Soc Nephrol. 2003;14(12):3217-32.
18. Schwab SJ, Christensen RL, Dougherty K, Klahr S. Quantitation of proteinuria by the use of protein-to-creatinine ratios in single urine samples. Arch Intern Med. 1987;147(5):943-4.

19. Xin G, Wang M, Jiao LL, Xu GB, Wang HY. Protein-to-creatinine ratio in spot urine samples as a predictor of quantitation of proteinuria. Clin Chim Acta. 2004;350(1-2):35-9.

20. Ubukata M, Takei T, Nitta K. Estimation of the 24-h urinary protein excretion based on the estimated urinary creatinine output. Clin Exp Nephrol. 2016;20(3):456-61.

21. Teo BW, Loh PT, Wong WK, Ho PJ, Choi KP, Toh QC, et al. Spot urine estimations are equivalent to 24-hour urine assessments of urine protein excretion for predicting clinical outcomes. Int J Nephrol. 2015;2015:156484.

22. Tangri N, Grams ME, Levey AS, Coresh J, Appel LJ, Astor BC, et al. Multinational assessment of accuracy of equations for predicting risk of kidney failure: a Meta-analysis. JAMA. 2016;315(2):164-74.

23. Sumida K, Nadkarni GN, Grams ME, Sang Y, Ballew SH, Coresh J, et al. Conversion of urine protein-Creatinine ratio or urine dipstick protein to urine albumin-Creatinine ratio for use in chronic kidney Disease screening and prognosis : an individual participant-based Meta-analysis. Ann Intern Med. 2020;173(6):426-35

24. Medina-Rosas J, Yap KS, Anderson M, Su J, Touma Z. Utility of urinary protein-Creatinine ratio and protein content in a 24-hour urine collection in systemic lupus Erythematosus: a systematic review and Meta-analysis. Arthritis Care Res. 2016;68(9):1310-9.

25. Kobayashi S, Amano H, Terawaki H, Ogura M, Kawaguchi Y, Yokoo T. Spot urine protein/creatinine ratio as a reliable estimate of 24-hour proteinuria in patients with immunoglobulin a nephropathy, but not membranous nephropathy. BMC Nephrol. 2019;20(1):306.

\section{Publisher's Note}

Springer Nature remains neutral with regard to jurisdictional claims in published maps and institutional affiliations.

Ready to submit your research? Choose BMC and benefit from:

- fast, convenient online submission

- thorough peer review by experienced researchers in your field

- rapid publication on acceptance

- support for research data, including large and complex data types

- gold Open Access which fosters wider collaboration and increased citations

- maximum visibility for your research: over $100 \mathrm{M}$ website views per year

At BMC, research is always in progress.

Learn more biomedcentral.com/submissions 